\section{Salmonella in Indian ready-to-cook poultry: antibiotic resistance and molecular characterization}

\author{
Raj Kamal Gautam, ${ }^{1}$ \\ Aarti S. Kakatkar, ${ }^{1}$ \\ Manisha N. Karani, ${ }^{1}$ Shashidhar R., ${ }^{1}$ \\ Jayant R. Bandekar ${ }^{2}$ \\ ${ }^{1}$ Food Technology Division and \\ ${ }^{2}$ Radiation Biology and Health Science \\ Division, Bhabha Atomic Research \\ Centre, Mumbai, India
}

\begin{abstract}
The availability and popularity of processed, ready-to-cook (RTC) poultry products are increasing in India. Though fresh poultry is known to be contaminated with Salmonella, the prevalence of this foodborne pathogen in RTC poultry products is not reported. Eighty-seven chilled and frozen RTC poultry samples of 4 different brands obtained from supermarkets and departmental stores in Mumbai were analyzed for the presence of Salmonella. The prevalence of Salmonella was higher (51\%) in chilled RTC samples as compared to the frozen RTC samples (5\%). The frozen RTC samples of one brand were free from Salmonella. S. Typhimurium $(75.2 \%)$ was the most prevalent serovar, followed by $S$. Enteritidis (23\%) and $S$. Weltevreden $(1.7 \%)$. A high percentage $(81.4 \%)$ of the isolates were found to be resistant to 5 or more antibiotics and class 1 integron, which has been shown to confer multi-drug resistance, was detected in $69.9 \%$ of the isolates. Multiple antibiotic resistance index of isolates was high (0.6) indicating the indiscriminate use of antibiotics during poultry farming. High genetic diversity was observed among the Salmonella serovars based on Pulsed Field Gel Electrophoresis profiles. Results showed the presence of multi-drug resistant Salmonella serovars in processed, chilled RTC poultry products marketed in Mumbai, India.
\end{abstract}

\section{Introduction}

Salmonella is one of the most important foodborne pathogens. Poultry meat, eggs and foods of animal origin are important sources of human Salmonella infections. ${ }^{1,2}$ The ubiquitous distribution of Salmonella in the natural environment, ${ }^{3}$ and its prevalence in many foods have made inspection a mandatory requirement world-wide. ${ }^{4-6}$ Salmonella is often transmitted to humans through the food chain, with over $95 \%$ of salmonellosis cases attributable to the consumption of undercooked or mishandled pork, poultry and eggs. ${ }^{6-8}$ A multistate outbreak of Salmonella Heidelberg infections linked to foster farm brand chicken has been reported. ${ }^{9}$

Emergence of multi drug resistant Salmonella has been reported worldwide and it is a major public health concern. ${ }^{6,10-}$ 12 The antimicrobial resistance is frequently associated with integrons, transposons, and plasmids, which are involved in horizontal transfer of antibiotic resistance genes among bacteria and increase in the overall resistance gene pool. ${ }^{11,13,14}$ Integrons are genetic elements able to capture, integrate and rearrange open reading frames (ORFs) embedded in variable regions of genes cassette units and convert them to functional genes by ensuring their correct expression. ${ }^{15}$ Integrons do not transfer themselves; instead facilitate transmission of antibiotic resistance genes via transposons or conjugative plasmids. ${ }^{16}$ Class 1 integron, the most common integron located on Salmonella genomic island 1 (SGI 1), has been detected in different Salmonella serovars such as $S$. Typhimurium, $S$. Bareily, $S$. Oslo, and $S$. Newport in several countries. ${ }^{4,10,13}$ There are reports on multidrug resistant Salmonella isolated from India. 4,13,17 However, incidence of Salmonella in RTC food samples in India is not well documented. Moreover there are very few studies on molecular characterization of these Salmonella isolates. ${ }^{4,18}$

Fresh poultry slaughtered in local shops is generally preferred by consumers in India. However, due to changes in life style and modernization, fresh chilled and frozen RTC poultry products has become readily available in retail high end shops and supermarkets in major cities. But, there are few studies on the presence of Salmonella in these RTC products from India. ${ }^{18}$ The aim of present study was to i) screen branded RTC poultry products from Mumbai for the presence of Salmonella, ii) study the antimicrobial resistance profile of Salmonella isolates and presence of class 1 integron in MDR strains and iii) characterize these isolates by Pulsed Field Gel Electrophoresis (PFGE).

\section{Materials and Methods}

\section{Sampling}

Forty eight chilled and thirty nine frozen RTC poultry samples of four differ-
Correspondence: Shashidhar R, Food Technology Division, Bhabha Atomic Research Centre, Mumbai, 400085 India.

Tel.: +91.22.25590564

Fax: +91.22.25505151/25519613

E-mail: shashi@barc.gov.in

Key words: Ready to Cook Poultry, Salmonella, Class 1 integron, Antibiotic Resistance, PFGE.

Acknowledgements: the authors acknowledge technical help from Mrs. Vaishali V. Mahale of Food Technology Division, B.A.R.C. We also thank Director, National Salmonella and Escherichia Centre, Central Research Institute, Kasauli, Himachal Pradesh, for serotyping the Salmonella isolates.

Contributions: RKG conceptualized the study, performed experiment work, data analysis, interpretation, and manuscript drafting; ASK performed experiment and helped in manuscript drafting and revision; JRB, MNK reviewed initial draft of manuscript; SR contributed in design of experiment, reviewed initial manuscript, approval of final version of manuscript to be published and is corresponding author of the manuscript.

Conflict of interest: the authors declare no potential conflict of interest.

Received for publication: 12 September 2016. Accepted for publication: 17 October 2016.

This work is licensed under a Creative Commons Attribution NonCommercial 4.0 License (CC BY-NC 4.0).

(C) Copyright R.K.Gautam et al., 2017

Licensee PAGEPress, Italy

Microbiology Research 2017; 8:6882

doi:10.4081/mr.2017.6882

ent brands were obtained from various supermarkets and departmental stores in Mumbai (Supplementary Table S1). The chilled RTC samples included mixed boneless chicken, leg cut, precut, soup pieces, kheema, assorted cut pieces, lollipops or drumsticks. The frozen RTC samples were comprised of sausages, kheema, cutlet, nuggets, tandoori chicken nuggets, tandoori chicken tikka, chicken samosa, salami slices, sheekh kebab, burger patty, lollipops, and spring roll. The frozen RTC samples contained ingredients such as flour, onion, water, spices and condiments (coriander leaves, garlic, ginger, red chili powder, coriander powder, curry powder, turmeric powder, green chili, kasoori methi, edible vegetable oils, soya bean granules, iodized salt, and acidity regulators-INS 330, 452). The samples were brought in ice and analyzed immediately. 


\section{Isolation of Salmonella}

The isolation of Salmonella was carried out as per US-FDA Bacteriological analytical manual $8^{\text {th }}$ edition. ${ }^{19}$ Microbiological media and antibiotic disc were from HiMedia Laboratories, Mumbai, India. Twenty five grams of poultry meat were homogenized in $225 \mathrm{~mL}$ lactose broth and incubated at $37^{\circ} \mathrm{C}$ for $24 \mathrm{~h}$. After the initial pre-enrichment step, the samples were further enriched in Tetrathionate broth and Rappaport-Vassiliadis medium at $43^{\circ} \mathrm{C}$ for $24 \mathrm{~h}$. A loopful culture from each of these media was streaked on Bismuth Sulfite Agar (BSA), Xylose lysine Deoxycholate Agar (XLDA), and Hektoen Enteric Agar (HEA) and plates were incubated at $35^{\circ} \mathrm{C}$ for $24 \mathrm{~h}$. After pre-enrichment, enrichment and plating on selective agar plates, typical Salmonella were isolated, and identified by biochemical tests like glucose test by Triple sugar iron agar (TSI), lysine decarboxylase test by Lysine Iron Agar (LIA), Urease test (Urea broth), IMViC test. ${ }^{19}$ Isolates were serotyped at the National Salmonella and Escherichia Centre, Central Research Institute, Kasauli, India.

\section{Antimicrobial susceptibility test}

Salmonella isolates were screened for antibiotic sensitivity using 15 different antibiotics by agar diffusion method as described by Clinical and Laboratory Standards Institute (CLSI). ${ }^{20}$ Salmonella isolates were grown in Mueller-Hinton broth (HiMedia) overnight to prepare inoculum in order to achieve colony suspension to match with McFarland standard 0.5 . The culture suspensions were evenly spread on Mueller-Hinton Agar (HiMedia) and antibiotic discs were placed on agar surface followed by further incubation at $37^{\circ} \mathrm{C}$ for $24 \mathrm{~h}$. Antibiotic resistance profiles were assigned according to CLSI as resistant (R), intermediate (I), or sensitive (S) after measuring average zone diameter. ${ }^{5}$ The type and concentration of antibiotics in disc were as follows, Ampicillin (AMP) $10 \mu \mathrm{g}$; Chloramphenicol (CHL) $30 \mu \mathrm{g}$; Streptomycin (STR) $25 \mu \mathrm{g}$; Cephalothin (CEP) $30 \mu \mathrm{g}$; Nalidixic acid (NAL) $30 \mu \mathrm{g}$; Ciprofloxacin (CIP) $10 \mu \mathrm{g}$; Ceftriaxone (CTR) $30 \mu \mathrm{g}$; Sulfamethizole (SMZ) 300 $\mu \mathrm{g} ; \quad$ Enrofloxacin (EFX) $10 \quad \mu \mathrm{g}$; Chlortetracycline (CTC) $30 \mu \mathrm{g}$; Kanamycin (KAN) $30 \mu \mathrm{g}$; Oxytetracycline (OTC) 30 $\mu \mathrm{g}$; Ofloxacin (OFX) $2 \mu \mathrm{g}$; Trimethoprim (TMP) $30 \mu \mathrm{g}$; and Tetracycline (TET) $30 \mu \mathrm{g}$ (HiMedia). Multiple antibiotic resistance (MAR) index is calculated as the ratio of number of resistant antibiotics to which organism is resistant to total number of antibiotics to which organism is exposed. ${ }^{6}$

\section{Molecular characterization of Salmonella}

Salmonella isolates were tested for the presence of invA gene by PCR amplification using the primers as previously described by Chiu et al. ${ }^{21}$ The Integron region was PCR amplified from MDR isolates using class 1 integron specific primers (CSL1 and CSR1) as previously described by Khan et al. ${ }^{13}$

PFGE was performed as per the Pulse Net USA protocol with $50 \mathrm{U}$ of XbaI (Bangalore Genei, Bangalore, India) at $37^{\circ} \mathrm{C} .{ }^{22}$ PFGE was carried out with Gene Navigator System (Amersham Biosciences, Sweden) in $1 \%$ agarose gel [Seakem ${ }^{\circledR}$ Gold Agar (Lonza, Rockland, USA)] in $0.5 \mathrm{X}$ Tris-Borate EDTA buffer at $9^{\circ} \mathrm{C}$. Pulse times ramped from 5 to $120 \mathrm{~s}$ during a $25 \mathrm{~h}$ run at $160 \mathrm{~V}$. Lambda ladder PFGE marker (New England Biolabs, Ipswich, MS, USA) was used as molecular weight standard. The gels were stained with ethidium bromide. The bands were analyzed visually and the 0 and 1 matrix (binary matrix) was developed based on the presence or absence of particular size band on the gel in all the samples. The matrix was analyzed using FREETREE software (Version 0.9.1.50, Folia Biologica, 2001). Strains differing by one band were considered as different pulsed field profiles (PFPs). The relatedness of the isolates was analyzed using $\mathrm{Nei}$ and $\mathrm{Li}$ /Dice distance similarity calculations and neighbor joining as the tree building algorithm. The output tree was visualized using the Tree View software (Version 1.5.2, Roderic D. M. 2005).

\section{Results and Discussion}

\section{Prevalence of Salmonella}

High percentage of chilled RTC poultry samples $(53 \%$ of brand 1 and $50 \%$ of brand
2) were positive for Salmonella as compared to frozen RTC samples (5\% samples of brand 4). The samples from brand 3 were free from Salmonella (Table 1). Present investigation shows both fresh chilled and processed frozen RTC poultry products are contaminated with Salmonella. Poultry meat and egg are established as a major source of contamination by Salmonella. 6,22 Presence of Salmonella in fresh poultry has been well reported worldwide. ${ }^{6,8}$ In the present study, samples were taken from very diverse products. The comparison between these products with respect to Salmonella incidence is difficult, but irrespective of the products, high incidence of Salmonella was found in all the samples except one. It was found that minimally processed, fresh RTC poultry samples (mixed boneless, soup pieces, mixed boneless, precut, drumstick and leg cut ) and also processed fresh/frozen RTC poultry samples (from brand 1 lollipops and kheema) were contaminated with $S$. Typhimurium and $S$. Enteritidis. The fresh RTC poultry (brand 1 and 2) comprised of both processed and un-processed poultry products. Therefore, there is a high level of the Salmonella incidence in these products (Table 1 and Supplementary Table S1). Out of 113 Salmonella isolates, $75.2 \%$ were $S$. Typhimurium, $23 \%$ were $S$. Enteritidis and $1.7 \%$ were $S$. Weltevreden (Table 1). Thirty four percent of Salmonella positive samples were contaminated with at least 2 serovars (Table 1 and Supplementary Table S1). S. Typhimurium and $S$. Enteritidis were the most frequently reported serovars associated with human foodborne illnesses and poultry industry in India. ${ }^{6,8}$ Also, $S$. Typhimurium is one of the most commonly detected serovars from animals used for food and retail meat in the USA. ${ }^{10}$

\section{Antibiotic resistance}

More than $80 \%$ of Salmonella isolates

Table 1. Isolation of Salmonella spp. from different brands of poultry.

\begin{tabular}{|c|c|c|c|c|}
\hline Brand & Total samples & Sample type & $\begin{array}{c}\text { Sample positive } \\
\text { for Salmonella (\%) }\end{array}$ & $\begin{array}{l}\text { Serotypes identified } \\
\text { (number of isolates) }\end{array}$ \\
\hline 1 & 34 & Chilled RTC & 52.9 & $\begin{array}{l}\text { S. Typhimurium (58) } \\
\text { S. Enteritidis (12) } \\
\text { S. Weltevreden (2) }\end{array}$ \\
\hline 2 & 14 & Chilled RTCa & 50 & $\begin{array}{l}\text { S. Typhimurium (23) } \\
\text { S. Enteritidis (12) }\end{array}$ \\
\hline 3 & 20 & Frozen RTC ${ }^{b}$ & $\mathrm{ND}^{\mathrm{c}}$ & $\mathrm{ND}^{\mathrm{c}}$ \\
\hline 4 & 19 & Frozen RTC ${ }^{b}$ & 5.2 & $\begin{array}{l}\text { S. Typhimurium (4) } \\
\text { S. Enteritidis (2) }\end{array}$ \\
\hline
\end{tabular}

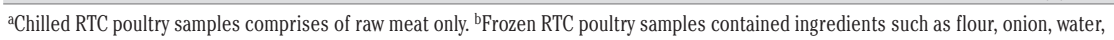
spices and condiments. ${ }^{\mathrm{N} D}$ stands for Not detected. 
were multi-drug resistant (MDR) with resistance to 5 or more different antibiotics. $S$. Typhimurium (17 isolates), $S$. Enteritidis (11 isolates) and $S$. Weltevreden (2 isolates) with MAR index from 0.5333 to 0.6 were resistant to more than 8 antibiotics belonging to different class of antibiotics (Table 2). Multidrug resistance has been reported in a number of serovars of Salmonella from different foods. ${ }^{13,17}$ Salmonella isolates from brand 1 and brand 2 were resistant to 9 different antibiotics; whereas, Salmonella isolates of brand 4 were resistant to 4 antibiotics (Table 2). Ninety percent of $S$. Typhimurium isolates were resistant to NAL, CTC, KAN, OTC and TET. All $S$. Enteritidis isolates were resistant to KAN and OTC, while more than $80 \%$ of isolates were resistant to NAL and CTC. Both the $S$. Weltevreden isolates were resistant to AMP, NAL, SMZ, CTC, KAN, OTC, and TMP (Table S2). The sensitivity pattern indicated that all isolates were sensitive to CHL, STR, CIP, CTR, EFX, and OFX (Supplementary Table S2).

A total of 19 antibiotic resistance pat- terns were observed. The most predominant antibiotic pattern was NAL, SMZ, CTC, KAN, OTC, TMP, TET (29 isolates) followed by AMP, CEP, NAL, SMZ, CTC, KAN, OTC, TMP, TET (16 isolates) (Table 2). Multiple antibiotic resistance (MAR) index of both $S$. Typhimurium and $S$. Enteritidis was 0.6 while that of $S$. Weltevreden was 0.53 (Table 2). The high MAR index indicates indiscriminate use of antibiotics in poultry farming for growth promotion, prophylaxis as well as therapeutic purposes. The injudicious use of antibiotics in poultry which has increased the emergence and maintenance of MAR bacteria in the environment has been reported. ${ }^{1,6}$

\section{Molecular characterization}

All the Salmonella serovars isolated from poultry were invA positive. The invA gene is located on Salmonella Pathogenicity Island 1 (SPI-1), which is essential for the invasion of host's epithelial cells by Salmonella. This gene is highly conserved in Salmonella serotypes and has been used as a potential target for Salmonella detec- tion. ${ }^{23}$ In a study of 630 different strains of Salmonella enterica, $99.4 \%$ of strains were found to harbour the invA gene. ${ }^{24}$ Whereas another study reported the presence of invA gene in Salmonella is not universal, as during their study out of 35 tested strains of Salmonella, 33 harboured sse $\mathrm{L}$ as well as invA virulence genes, however two strains (Salmonella Molade and Salmonella München), did not harbour the invA virulence gene. ${ }^{25}$

Seventy percent of the Salmonella isolates carried the class 1 integron. Class 1 integron specific PCR detected double amplicons (1 kb and $1.2 \mathrm{~kb}$ ) in $53.9 \%$ isolates (Supplementary Figure S1). The rest of the class 1 integron positive isolates showed multiple bands. These results were consistent with earlier studies. ${ }^{11,26-28}$ Integrons may carry antibiotic resistance gene cassettes, which confer resistance to antimicrobials. ${ }^{13}$ In the present study, $82 \%$ of the integron positive isolates were MDR. But interestingly, $18 \%$ of the integron positive isolates were non-MDR (resistant to less than 5 antibiotics). Ampicillin and

Table 2. Antibiotic resistance pattern of Salmonella spp. isolated from poultry.

\begin{tabular}{|c|c|c|c|c|c|}
\hline S. no & Antibiotic patterna & MAR $^{b}$ index & Ser & vars (number of iso & \\
\hline & & & Brand 1 & Brand 2 & Brand 4 \\
\hline 1 & AMP, CEP, NAL, SMZ, CTC, KAN, OTC, TMP, TET & 0.6 & $\begin{array}{l}\text { S. Typhimurium (5); } \\
\text { S. Enteritidis (7) }\end{array}$ & S. Typhimurium (4) & \\
\hline 2 & AMP, CEP, NAL, SMZ, CTC, KAN, OTC,TET & 0.5333 & S. Enteritidis (3) & & \\
\hline 3 & AMP, CEP, NAL, SMZ, KAN, OTC, TMP, TET & 0.5333 & S. Typhimurium (5) & & \\
\hline 4 & AMP, NAL, SMZ, CTC, KAN, OTC, TMP, TET & 0.5333 & $\begin{array}{l}\text { S. Typhimurium (3); } \\
\text { S. Weltevreden (2) }\end{array}$ & & \\
\hline 5 & CEP, NAL, SMZ, CTC, KAN, OTC,TMP, TET & 0.5333 & & $S$. Enteritidis (1) & \\
\hline 6 & NAL, SMZ, CTC, KAN, OTC, TMP, TET & 0.4666 & $\begin{array}{l}\text { S. Typhimurium (18); } \\
\text { S. Enteritidis (4) }\end{array}$ & S. Typhimurium (7) & \\
\hline 7 & NAL, CTC, KAN, OTC, TMP, TET & 0.4 & & S. Typhimurium (1) & \\
\hline 8 & NAL, SMZ, KAN, OTC, TMP, TET & 0.4 & & S. Enteritidis (3) & \\
\hline 9 & NAL, SMZ, CTC, KAN, OTC, TET & 0.4 & S. Typhimurium (10) & & \\
\hline 10 & AMP, NAL, CTC, KAN, OTC, TET & 0.4 & S. Typhimurium (5) & S. Typhimurium (1) & \\
\hline 11 & NAL, SMZ, KAN, OTC, TMP & 0.3333 & S. Typhimurium (1) & & \\
\hline 12 & AMP, CTC, KAN, OTC, TET & 0.3333 & & $\begin{array}{l}\text { S. Typhimurium (1); } \\
\text { S. Enteritidis (1) }\end{array}$ & \\
\hline 13 & NAL, CTC, KAN, OTC, TET & 0.3333 & & $\begin{array}{l}\text { S. Typhimurium (3); } \\
\text { S. Enteritidis (2) }\end{array}$ & \\
\hline 14 & NAL, CTC, OTC, TET & 0.2666 & & & $\begin{array}{l}\text { S. Typhimurium (4) } \\
\text { S. Enteritidis (2) }\end{array}$ \\
\hline 15 & CTC, KAN, OTC, TET & 0.2666 & & $\begin{array}{l}S \text {. Typhimurium (3); } \\
\text { S. Enteritidis (3) }\end{array}$ & \\
\hline 16 & CTC, OTC, TET & 0.2 & & S. Typhimurium (2) & \\
\hline 17 & AMP, NAL, KAN & 0.2 & S. Typhimurium (1) & & \\
\hline 18 & NAL, KAN & 0.1333 & S. Typhimurium (2) & & \\
\hline 19 & NAL & 0.0666 & S. Typhimurium (4) & & \\
\hline
\end{tabular}


tetracycline resistance of these isolates may be due to presence of genes responsible for antibiotic resistance on class 1 integron. ${ }^{29}$ However, resistance to NAL could be due to mutation in the target genes of proteins of these antibiotics. ${ }^{14}$ Resistance to KAN, and OTC could be attributed to inhibition of protein synthesis. ${ }^{26}$ It was found that 26 MDR strains of Salmonella lacked the class 1 integron. This could be due to the presence of antibiotic resistance genes elsewhere on the chromosome as reported earlier. ${ }^{11,26}$

Vast genetic diversity was observed among the $S$. Typhimurium and $S$. Enteritidis isolates. Eighty-five $S$. Typhimurium isolates were clustered into twenty different PFGE patterns (Supplementary Figure S2). The major cluster of $S$. Typhimurium comprised of 13 isolates from brand 2 and 4 samples (Supplementary Figure S2). Twenty six $S$. Enteritidis isolates were grouped into 5 PFGE patterns. Fifteen $S$. Enteritidis isolates from brand 1,2 and 4 samples were clustered in 2 PFGE patterns (Supplementary Figure S3). The PFGE patterns clearly indicated that Salmonella spp. isolated from the poultry samples were of same clonal origin. For example, the PFGE pattern of $S$. Typhimurium isolate no 445 from brand 4 was same as that of $S$. Typhimurium isolate no 501 from brand 2 . Also, PFGE patterns of $S$. Enteritidis isolates no 32,123 and 458 were same; however, these serotypes were isolated from brand 1, 2 and 4, respectively. Previous study on genetic diversity of Salmonella showed high diversity in Salmonella isolates obtained from different food samples. ${ }^{30}$

However, there is no PFGE data bank like PulseNet (http://www.cdc.gov/pulsenet/) program in India. Therefore, it is very difficult to trace Salmonella isolated from different regions and tag them to the source of origin. Moreover, serovars isolated at different time periods of the year also showed same PFGE pattern, for example, $S$. Enteritidis isolate no 32 and 242 were from same brand but they were isolated in different months. These results indicate that same Salmonella serovars are present in poultry products from different brands. Similarity in PFGE patterns could be due to cross-contamination that most likely happened during processing and handling, which would account for the isolation of same organism at different stages of processing from different meat carcasses. ${ }^{31}$ One of the sources of contamination could be the feed used in the poultry farms. ${ }^{32,33}$

\section{Conclusions}

Present study demonstrates the high incidence of Salmonella in poultry samples. We also observed high percentage of Salmonella isolates resistant to multiple antibiotics. Our study also reveals that, the modern food processing methods adopted by poultry industry are insufficient to produce microbiologically safe poultry products. We observed that minimally processed fresh chilled RTC poultry products and processed, frozen RTC poultry samples are contaminated with $S$. Typhimurium, $S$. Enteritidis and $S$. Weltevreden serovars. It may be due to poor processing practices followed by the poultry industry. Recently more stringent food laws are being implemented to improve the processed food quality in India.

\section{References}

1. Shekhar C, Singh SP. Anti-microbial resistance and molecular characterization of Salmonella serovars from man and animals. Indian $\mathrm{J}$ Anim Sci 2014;84:368-72.

2. World Health Organization. Health topics - Salmonella. 2013. Available from: http://www.who.int/topics/Salmonella/e $\mathrm{n} /$

3. World Health Organization. Factsheet Salmonella (non-typhoidal) Factsheet No139 updated August 2013. Available from: http://www.who.int/mediacentre/factsheets/fs139/en/

4. Kakatkar AS, Pansare LS, Gautam RK, et al. Molecular characterization of antibiotic resistant Salmonella isolates from Indian foods. Food Res Int 2011;44:3272-5.

5. Saroj SD, Shashidhar R, Dhokane V, et al. Microbiological evaluation of sprouts marketed in Mumbai, India, and its suburbs. J Food Protect 2006;69: 2515-8.

6. Singh S, Yadav, AS, Singh SM, Bharti P. Prevalence of Salmonella in chicken eggs collected from poultry farms and marketing channels and their antimicrobial resistance. Food Res Int 2010;43: 2027-30.

7. Magistrali C, Dionisi AM, De Curtis P, et al. Contamination of Salmonella spp. in a pig finishing herd, from the arrival of the animals to the slaughter house. Res Vet Sci 2008;85:204-7.

8. Suresh T, Hatha AAM, Harsha HT, Lakshmanaperumalsamy P. Prevalence and distribution of Salmonella serotypes in marketed broiler chickens and processing environment in Coimbatore city of southern India. Food Res Int 2011;44:823-5.

9. Centre for Disease Control and Prevention. Multistate outbreak of Salmonella Heidelberg infections linked to foster farms brand chicken. Centre for Disease Control and Prevention; 2013. Available from: http://www.cdc.gov/Salmonella/heidelberg-10-13/index.html.

10. Louden BC, Haarmann D, Han J, et al. Characterization of antimicrobial resistance in Salmonella enterica serovar Typhimurium isolates from food animals in the U.S. Food Res Int 2011;45:968-72.

11. Vo AT, Van Duijkeren E, Fluit AC, et al. Antibiotic resistance, integrons and Salmonella genomic island 1 among non-typhoidal Salmonella serovars in The Netherlands. Int J Antimicrob Ag 2006;28:172-9.

12. Zhao S, Datta AR, Ayers S, et al. Antimicrobial-resistant Salmonella serovars isolated from imported foods. Int J Food Microbiol 2003;84:87-92.

13. Khan AA, Elizabeth P, Nawaz MS, et al. Identification and characterization of class 1 integron resistance gene cassettes among Salmonella strains isolated from imported seafood. Appl Environ Microbiol 2009;75:1192-6.

14. Davies J. Inactivation of antibiotics and the dissemination of resistance genes. Science 1994;264:375-82.

15. Cambray G, Guerout AM, Mazel D. Integrons. Annu Rev Genet 2010;44: 141-66.

16. Zhang T, Zhang XX, Ye L. Plasmid metagenome reveals high levels of antibiotic resistance genes and mobile genetic elements in activated sludge. PLoS One 2011;6:e26041.

17. Pui CF, Wong WC, Chai LC, et al. Salmonella: a foodborne pathogen. Int Food Res J 2011;18:465-73.

18. Kanatt SR, Rao MS, Chawla SP, Sharma A. Shelf-life extension of convenience meat products sold in Indian supermarkets by radiation processing. Radiat Phys Chem 2010;79:153-1263.

19. United States Food and Drug Administration. Online bacteriological analytical manual, revised 8th edition. United States Food and Drug Administration, Arlington; 2012. Available from: http://www.cfscan. fda.gov/ebam/bam-html.

20. Clinical and Laboratory Standard Institute. Performance standards for antimicrobial susceptibility testing; 18th informational supplement M100MS22, Wayne, PA, USA: Clinical and 
Laboratory Standard Institute; 2012.

21. Chiu CH, Ou, JT. Rapid identification of Salmonella serovars in faeces by specific detection of virulence genes, invA and $\mathrm{spvC}$, by an enrichment broth culture multiplex PCR combination assay. J Clin Microbiol 1996;34:2619-22.

22. Hunter SB, Vauterin P, Lambert-Fair MA, et al. Establishment of a universal size standard strain for use with the PulseNet standardized pulsed-field gel electrophoresis protocols: converting the national databases to the new size standard. J Clin Microbiol 2005;43: 1045-50.

23. Li Q, Cheng W, Zhang D, et al. Rapid and sensitive strategy for Salmonella detection using an invA gene-based electrochemical DNA sensor. Int J Elecrochem Sci 2012;7:844-56.

24. Rahn K, De Grandis SA, Clarke RC, et al. Amplification of an invA gene sequence of Salmonella Typhimurium by polymerase chain reaction as a specific method of detection of Salmonella. Mol Cell Probe 1992;6:271-9.
25. Krzyzanowski JF, Zappelini L, Martone-Rocha S, et al. Quantification and characterization of Salmonella spp. Isolates in sewage sludge with potential usage in agriculture. BMC Microbiol 2014;14:263.

26. Randall LP, Cooles SW, Osborn MK, et al. Antibiotic resistance genes, integrons and multiple antibiotic resistance in thirty five serotypes of Salmonella enterica isolated from humans and animals in UK. J Antimicrob Chemoth 2004;53:208-16.

27. Rao S, Maddox CW, Hoien-Dalen P, et al. Diagnostic accuracy of class 1 Integron PCR method in detection of antibiotic resistance in Salmonella isolates from swine production systems. J Clin Microbiol 2008;46:916-20.

28. Ribeiro VB, Lincopan N, Landgraf M, et al. Characterization of class 1 integrons and antibiotic resistance genes in multidrug resistant Salmonella enterica isolates from foodstuff and related sources. Brazilian J Microbiol 2011;42: 685-92.
29. Carattoli A, Filetici E, Villa L, et al. Antibiotic resistance genes and Salmonella genomic island 1 in Salmonella enterica serovars Typhimurium isolated in Italy. Antimicrob Agents Chemother 2002; 46:2821-8.

30. Saroj SD, Shashidhar R, Bandekar JR. Note. Genetic diversity of food isolates of Salmonella enterica serovars Typhimurium in India. Food Sci Technol Int 2008;14:151-6.

31. Li Q, Skyberg JA, Fakhr MK, et al. Antimicrobial susceptibility and characterization of Salmonella isolates from processed bison carcasses. Appl Environ Microbiol 2006;72:3046-9.

32. Maciorowski KG, Jones FT, Pillai SD, Ricke SC. Incidence, sources, and control of foodborne Salmonella spp. in poultry feeds. World Poultry Sci J 2004;60:446-57.

33. Lawley R. Salmonella. Food Safety Watch updated on February 2nd 2003; 2013 Available from: http://www.foodsafetywatch.org/factsheets/Salmonella/ 